\title{
25 Research Square \\ Translation, Adaptation and Validation of an Arabic Version of Human Resource Practices Scale among Nurses
}

Heba El-Gazar ( $\square$ heba.emad@nur.psu.edu.eg )

Port Said University https://orcid.org/0000-0002-0185-859X

Mohamed Zoromba

Mansoura University

Abdel-Hady El-Gilany

Mansoura University Faculty of Medicine

Research

Keywords: Human Resource Practices, Arabic version, Validation, Reliability, Nurses

Posted Date: April 1st, 2021

DOI: https://doi.org/10.21203/rs.3.rs-355220/v1

License: @ (i) This work is licensed under a Creative Commons Attribution 4.0 International License. Read

Full License 


\section{Abstract}

Background: Human resource practices (HRP) have a unique role in healthcare organizations, especially among nurses. Therefore, a valid and reliable tool to measure HRP is crucial. The present study aimed to translate, culturally adapt, and validate the Human resource practices (HRP) scale into Arabic language among nurses.

Methods: A methodological study was applied in a sample of 328 nurses from 16 hospitals in Port-Said, Egypt. Face, content, construct and concurrent validity were assessed. Cronbach's alpha coefficients and intraclass correlation coefficient (ICC) to test reliability were evaluated.

Results: The Arabic version of HRP scale had good content validity with I-CVI ranged from 0.727 to 1 and S$\mathrm{CVI}$ with the average approach 0.961 . Confirmatory factor analysis showed a better fit for the second-order model consisting of performance enhancement and employee support factors (CFI, NFI and RMSEA $=0.932$, 0.926 , and 0.064 ; respectively). The Arabic version of HRP scale correlated significantly with performance excellence and nurses' performance ( $r=0.701$, and 0.565 ; respectively), indicating good concurrent validity. Internal consistency with Cronbach's alpha was 0.95 and the intra-class correlation coefficient was 0.91 for the total scale showed good reliability.

Conclusion: The Arabic version of HRP scale showed evidence of validity and reliability, and it could be recommended for use in clinical and research settings to assess HRP among Arabic nurses.

\section{Introduction:}

Human resource practices (HRP) play a key role in determining the survival and effectiveness of contemporary organizations and may even be the single most important determinant of an organization's performance and success [1]. In healthcare organizations, HRP are unique and had specific responsibilities [2]. Healthcare organizations can accomplish an upper hand over competitors through managing their human resources effectively as it can increase profitability, productivity, market value and growth [3].

Effective HRP support health care organizations in achieving their objectives and help to promote a highperformance culture. HRP are the way to achieve performance excellence and are considered the determinant of health workforce performance [4]. Indeed, the nursing staff is considered the most precious resource in health care organizations, and promoting HRP in nursing reflects the cutting edge of advancement in the nursing field [5].

Nursing HRP has been defined as the healthcare organizational practices associated with hiring, firing, developing, and rewarding nurses who work for the healthcare organization [6]. There are five areas associated with effective HRP in nursing; nurses' recruitment, selection, retention of competent nurses, developing and promoting and job termination [7, 8]. Roussel [5] added that performance appraisal, compensation, and safety are also main areas of nursing HRP.

HRP scale is a refined and validated scale. The scale was developed by Villajos et al. [9] to assess employees' perceptions of HRP including performance enhancement practices as well as employee support practices. It is 
noteworthy that, the previous HRP researches focus mainly on performance enhancement practices and have ignored employee support practices which are considered a radical critique of those writings [10]. Moreover, this scale responded to HRP researchers' recommendation of measuring HRP from subordinates' perceptions. Previously, HRP were measured through managerial opinions and perceptions of subordinates may vary, producing a gap between managers' objectives and subordinates' perceptions [11].

HRP considered as one of the most significant obligations within health care organizations [12]. Generally, nurses considered as one of the largest healthcare groups in every country in the world [13]. Consequently, utilization of human resources practices among nurses is critical to health care organizations [14].

With this regard, it is recommended to conduct more researches exploring HRP in different healthcare settings [15]. Lunnan and Traavik [16] added that the HRP and its standardization are affected by cultural differences. However, there is a lack of a valid tool measuring HRP in the Arabic language among nurses according to the best of researchers' knowledge. In sum, the present study aims to translate, culturally adapt, and validate the HRP scale into Arabic language among nurses.

\section{Subjects And Methods: \\ Study design:}

The study utilized a methodological research design (Cross-sectional study with a longitudinal component for reliability).

\section{Settings:}

Data were collected from 16 hospitals (out of 17 hospitals) in Port-Said city, Egypt, accepted to participate in the study. Eight hospitals are affiliated to the Ministry of Health, two follow Health Insurance Hospitals, and six are private hospitals. Data collected from beginning of October 2018 to the end of March 2019.

\section{Sampling method and techniques:}

The target population included all nurses in the identified hospitals at the time of data collection $(N=1331)$. Current study included nurses who had experienced more than six months in the current work setting. The nurses who were in labor, sickness and childcare vacations during the data collection period were omitted.

The sample size was estimated depending on the item sample ratio method. Per rule of thumb, it is instructed to recruit a minimum of 10 participants in each item of the scale [17]. The total participants needed to be 240 . Assuming a $10 \%$ dropout rate, an additional 24 participants were added to be 264 . This increased to 335 to achieve sufficient power and precision for the study [18]. Due to incompleteness, seven questionnaires were excluded. Hence, a sample of 328 nurses was recruited for the study. The sample size was distributed proportionally according to total nurses in each hospital. A systematic random sample from each hospital was selected from the list of all nurses available at the hospital administration.

\section{Measures:}

\section{The human resource practices (HRP) scale}


The HRP scale was developed by Villajos et al. [9], in English to assess perceptions of employees of human resource practices. It is containing 24 items covering two bundles. The first is performance enhancement bundle and the second is employee support bundle. Performance enhancement bundle include five practices are training and development, contingent pay and rewards, performance appraisal, recruitment and selection, and a competitive salary. Employment security, work-life balance, and exit management in the employeesupport bundle. The 24 items measuring along a 5-point Likert-type scale as follows: not at all (1), very little (2), some (3), a fair amount (4) and a lot (5). Demographics questionnaire sheet was attached to the scale to collect data related to gender, age, level of education, position, and years of experience in nursing.

\section{Criterion scales:}

Baldrige dimension scale [19] and six dimension scale of nursing performance (6-D) [20] were used as external criterion for measuring concurrent validity. Baldrige dimension scale was validated in Arabic by Badri et al. [21] to assess Baldrige Health Care Criteria for performance excellence. The scale composed of 115 items measuring seven categories; leadership, information and analysis, strategic planning, human resource development and management, process management, organization performance results, focus on and satisfaction of patients and other stakeholders. Those seven categories subdivided to 28 dimensions. The responses of participants have collected a long 7-point Likert-type scale.

Six dimension scale of nursing performance (6-D) validated in Arabic by Miloud [22]. It composed of 52 items under six dimensions namely leadership, critical care, teaching/collaboration, planning/evaluation, interpersonal relations/communication, and professional development. Each item was scored using a 4-point scale.

\section{Procedures:}

The translation and culture adaptation of the HRP scale followed international guidelines of cross-cultural adaptation of health questionnaires [23]. The process was performed in five stages: forward translation, synthesis of the translated versions, back translation, expert committee, and test of the pre-final version. Psychometric testing (validity and reliability) was calculated to the final Arabic version of HRP scale (Fig. 1).

\section{Stage l: forward translation}

The HRP scale was translated from the original language, English; into Arabic by two separate bilingual translators whose mother tongue is Arabic. One translator was a fluent English nurse manager who is familiar with the terminology and construction of HRP in healthcare. The other was a certified translator. This step generated two forward-translated versions of the instrument (T1.T2).

\section{Stage II: synthesis of the translated versions}

The two translators and the first author evaluated the two translated versions ( $T 1 \& \mathrm{~T} 2)$, creating an agreed a synthetic Arabic version of the HRP scale (T1-2).

\section{Stage III: back translation}

The synthetic Arabic version of the HRP scale (T1-2) was back translated into English by two other independent qualified translators, one of them was bicultural. The two translators were blind to the original 
English version. As a result, two back-translated versions (BT1\& BT2) were produced.

\section{Stage IV: expert committee}

The HRP scale was cross-culturally adapted by a multidisciplinary bilingual expert panel consisting of the four translators involved in the forward and back-translations, one nursing administration university professor, and one nursing director with a master degree in nursing administration. The committee was asked to review produced material (T1.T2, T12, BT1, and BT2) and the original version. The necessary modifications were introduced by consensus to realize semantic, experiential, idiomatic, and conceptual equivalence between the original version and the target one. At the end of this stage, researchers produced a consolidated pre-final version of the HRP scale in Arabic.

\section{Stage V: test of the pre-final version (pilot study)}

In this stage, 30 nurses (not included in the full-scale study) tested the pre-final Arabic version of the HRP scale. After that, the cognitive debriefing process was utilized, each nurse who completed the scale was interviewed about the meaning of each item and the chosen response. A minor modification was done at this stage and final Arabic version was produced.

\section{Psychometric testing of the Arabic version of the HRP scale Validity}

Face, content, construct, and concurrent validity were used to validate the HRP scale into Arabic. Face validity is the degree to which the Arabic version of the current scale measures superficially HRP. Eleven experts valued the scale readability, feasibility, formatting and style consistency, and language clarity [24]. All experts assured that the proposed Arabic version has good face validity for assessing HRP.

Content validity evaluates the degree to which the Arabic version of the current scale includes all the key elements related to HRP [25]. Eleven experts in the field of nursing administration, business administration and human resources management examine the content validity for the Arabic version of HRP scale. The experts were asked independently to review each item using 4 points ordinal scale $(1=$ disagree, $2=$ need modification, 3 = agree, 4 = highly agree) [26].

The content validity index was estimated at the item level (I-CVI) and scale level (S-CVI). To obtain the content validity index at the item level (I-CVI), the number of experts judging the item as relevant or clear (rating 3 or 4 ) were divided by the total number of experts. The item will be suitable if the I-CVI exceeds 0.79 . It needs to be revisited if the $\mathrm{I}-\mathrm{CVI}$ is between 0.70 and 0.79 . It is removed if the $\mathrm{I}-\mathrm{CVI}$ is less than 0.70 . The content validity index for the entire scale (S-CVI) was assessed by the S-CVI with the average approach, by summing all I-CVI for relevancy divided by items number. The scale as a tool was considered to be valid if S-CVI $\geq 0.90$ [25].

The construct validity examines the degree to which the Arabic version of HRP scale in line with an established theory or hypothetical construct. The Arabic version of HRP scale construct validity was evaluated by confirmatory factor analysis (CFA). The criteria for conducting the CFA were evaluated using the Kaiser-MeyerOlkin (KMO) test of sampling adequacy with value $>0.6$ and the Bartlett Test of Sphericity with the statistical 
significance level $P<0.05$. CFA was conducted in terms of item loading and goodness of fit estimation using maximum likelihood (ML). Item loading should be greater than 0.30 [27].

Goodness of fit was assessed for two models. The first (model A) was first-order confirmatory factor analysis consisted of the 8 practices and 24 items. The second was a second-order confirmatory factor analysis combining the practice into two bundles (model B). Goodness of fit evaluated using comparative fit index $(\mathrm{CFI})$, the normed fit index (NFI), and root mean square error of approximation (RMSEA), considering the usual values for comparative fit index (CFI) and normed fit index $(\mathrm{NFI}) \geq .90$ and root mean square error of approximation (RMSEA) $<0.08$ [17].

To test the concurrent validity, a correlation coefficient computed between the Arabic version of HRP scale and some external criterion. The valid criterions were Baldrige dimension scale to assess performance excellence, and six-dimension scale to assess nurses' performance (6-D). This is based on the literature's depiction of an existing relationship between HRP and achieving performance excellence in healthcare organizations [12] and increased level of nurses' performance [28]. The Arabic version of HRP scale considered valid if its scores correlate highly with scores on the criterion. Coefficients of .70 or higher are desirable [29].

\section{Reliability}

The reliability of the Arabic version of HRP scale means the scale ability to yield consistent consistency results. To investigate reliability, internal consistency and test-retest were applied. Internal consistency was examined by Cronbach's alpha reliability coefficients. Cronbach's alpha value of 0.50-0.70 was acceptable while 0.70 or higher shows good homogeneity among the items [30]. Two weeks' test-retest reliability was conducted with a subsample of 85 nurses and was tested by intra-class correlation coefficient (ICC). Correlation coefficient ( $r$ ) values are considered good if $r \geq 0.70$ [31].

\section{Ethical consideration}

- Permission for the translation, adaptation and applying psychometric testing of the scale was obtained from the originators of the scale.

- Nurses' informed consent was taken after an explanation of the study aim.

- Nurses recruited in this study were confirmed about the confidentiality of the information collected and that they can refuse or withdraw without penalty at any time.

\section{Statistical analysis:}

Data were analyzed with SPSS version 24 (IBM corporation, IL, Chicago, USA) and IBM AMOS V.22.0 for CFA. The content validity index was calculated at the item level (I-CVI) and scale level (S-CVI). Pearson's correlation coefficient ( $r$ ) was calculated to measure the correlations between the Arabic version of HRP scale performance excellence and nursing performance. CFA with maximum likelihood estimation was used for validation. Goodness of fit was evaluated using comparative fit index (CFI), the normed fit index (NFI), and root mean square error of approximation (RMSEA). Inter-class correlation (spearman $r$ ) was used to measure intra- 
rater correlation. Cronbach's alpha was calculated to measure the internal consistency between items. $\mathrm{P} \leq 0.05$ was considered statistically significant.

\section{Results:}

\section{Demographic data}

Among the 328 studied nurses, 204 (62.2\%) were working in Ministry of Health hospitals. The majority (87.5\%) of them were females. Ages ranged from 18 to 50 with a mean of 29.97 years $(S D=7.02)$. More than one third $(36.8 \%)$ of the studied nurses had a bachelor degree in nursing education. In relation to position, $73.2 \%$ of them were staff nurses, $15.8 \%$ were head nurses, $9.8 \%$ were members in hospital committees, and $1.2 \%$ were nursing directors. The total years of experience in nursing ranged from 1 to 28 years with a mean of 8.32 years $(S D=6.36)$.

\section{Content validity}

Content validity index at the item level $(\mathrm{I}-\mathrm{CVI})$ and scale level using average approach (S-CVI) presented in table (1). According to the table, content validity index for each item (I-CVI) ranged from 0.727 to 1 and the S-CVI for relevance was 0.961 .

Kaiser-Meyer-Olkin (KMO) measure and Bartlett's test to determine the adequacy of performing a CFA on the selected data presented that the $\mathrm{KMO}$ was 0.902 , indicating the adequacy of the present sample. The significant of Bartlett's Test of Sphericity was less than 0.001, indicating that the CFA was justified in the present dataset.

Items loading were presented in table (2). The Arabic version of HRP scale had items loading ranging from .53 to .87 . The lowest loading was observed for question corresponding to training and development (item2). Meanwhile, the highest loadings were observed for question corresponding to performance appraisal and employee-support practices (items 8 \& 17).

Goodness of fit for CFA models (model A and model B) estimated by MI was studied. Reference to model B which gathering the eight practice and 24 items into two bundles provided good model fit with CFI, NFI and RMSEA 0.932, 0.926 and 0.064 ; respectively. Whereas, the model A with 8 practice and 24 items is close to being acceptable as $\mathrm{CFI}$ and NFI were 0.902 and 0.872 ; respectively and RMSEA was 0.073 . When comparing the two models, it is obvious that model $\mathrm{B}$ had better fit than model $\mathrm{A}$.

\section{Concurrent validity}

Arabic version of HRP scale correlated with performance excellence and nurses' performance scales. Arabic version of HRP scale had significant positive correlation with performance excellence $(r=.701, P<.001)$ and nurses' performance $(r=.565, \mathrm{P}<.001)$ indicating concurrent related validity of the Arabic version of HRP scale. 


\section{Reliability}

The internal consistency of the Arabic version of HRP scale measured with Cronbach's alpha coefficient and it was 0.95 . In addition, the stability of the scale assessed by two-week test-retest reliability showed an intraclass correlation coefficient (ICC) 0.91 for the scale (Table 3).

\section{Discussion:}

The Arabic version of HRP scale demonstrated high content validity values, meaning that the scale involves all the major elements related to the human resource practices. This result indicates similar patterns and good agreement between both English and Arabic versions. The loading of each scale item showed that the scales meet Carmines \& Zeller' [27] criterion of having items loading more than 0.30 . This indicated a validation of the Arabic version of HRP scale items to the underlying constructs.

The study result found that item two (the opportunity to develop new skills and knowledge for my current job or for possible future positions) corresponding for training and development had the lowest contribution to the scale. This may be due to that the participants realize they could gain skills and knowledge from other sources as the internet without need organizational support. In the same context, item eight (a fair evaluation of my performance) corresponding to performance appraisal, and item 17 (a work contract that offers job security) corresponding to employment security had the highest contribution to the scale. This may be due to the nature of human beings that seek equity and security in work settings.

Findings from the CFA revealed that the second-order model combining the eight practices into two bundles had a better fit. This finding is parallel to those of authors of the original scale who proved that the two-bundle model had the best model fit. This finding agreed with a systematic literature review study done in SubSaharan, Africa searching in seven databases on the impact of human resource management on hospitals performance, concluded that most of the studies that investigated HRM adopted bundles gathering practices from multiple HRM themes, rather than individual practices [32].

Regarding concurrent validity, the present study assessed it through Arabic version of HRP scale correlation with health care organization performance excellence and nurses' performance. The Arabic version of HRP scale total scores had a significant positive correlation with performance excellence and nurses' performance. Such a relationship can be explained by when nurses receive support from their work setting on a professional and personal level, they do all of the best and exert more effort for their organizations.

The positive relationship between HRP and performance excellence was supported by Evans and Lindsay [33], who asserted that managers can achieve performance excellence through HRP. As well, Zink [34], stressed on the role of human resources practices in leading organizational excellence models. Besides, several studies provide evidence that HRP had a positive relationship with nurses' performance. One of those studies, a study in Ghana, studied the relationship between HRP and perceived performance of psychiatric nursing and reinforced that there was a significant positive correlation between the two variables [35]. In the same line, Gunawan et al. [36], mentioned that one consequence of human resource management in nursing is better job performance 
Concerning the Arabic version of HRP scale reliability, The Arabic version of HRP scale showed good reliability in terms of homogeneity and stability. These results go in line with the original English version which presented good scale reliability, providing a solid base for future academic and clinical implementation.

The main contribution of the present study is to provide an Arabic tool to health care practitioners and academics to assess HRP in health care organizations from the nurses 'perspective. One limitation was that all participants were nurses. Therefore, it needed to be confirmed to all health care practitioners. In addition, this study needs to generalize in more health care facilities in Egypt.

\section{Conclusions}

It could be concluded that the Arabic version of HRP scale had good validity and reliability and the scale can be used in clinical and research settings to evaluate HRP in health care organizations from nurses' perspectives. The present findings retained the 24 items and confirmed the two bundles approach of HRP scale proposed by the original English version.

\section{Abbreviations}

HRP: Human Resource Practices

ICC: Intra-class Correlation Coefficient

I-CVI: Item Content Validity Index

S-CVI: Scale Level Content Validity Index

CFA: Confirmatory Factor Analysis

6-D: Six Dimension Scale of Nursing Performance

KMO: Kaiser-Meyer-Olkin Test

ML: Maximum Likelihood

CFI: Comparative Fit Index

NFI: Normed Fit Index

RMSEA: Root Mean Square Error of Approximation

\section{Declarations}

\section{Ethical approval and consent to participate}

According to national low and regulation, there is no need to obtain ethical approval for this study as it not involves unethical behavior, clinical trials on humans or animals' experiments. Nurses' informed consent was 
taken from participated nurses after an explanation of the study aim.

\section{Consent for publication}

Not applicable

\section{Availability of data and materials}

The datasets used and/or analysed during the current study are available from the corresponding author on reasonable request

\section{Competing interests}

The authors declare that they have no competing interests.

\section{Funding}

This research did not receive any specific grant from any funding agencies.

\section{Authors contributions}

HE has contributed by developing the study design, collecting the data, and drafting the manuscript. MZ has contributed by conducting the statistical analyses. AE has contributed by revising the manuscript critically. All authors approved the final manuscript.

\section{Acknowledgements}

The authors acknowledge all nurses participated in this study.

\section{Author information}

Faculty of Nursing, Port-Said University, Egypt

Heba Emad El-Gazar

Faculty of Nursing, Mansoura University, Egypt

Mohamed Zoromba

Faculty of Medicine, Mansoura University, Egypt. 


\section{References}

1. Sims RR, Bias SK. Human resources management issues, challenges and trends: "Now and around the corner." USA: Information Age Publishing Incorporated; 2019.

2. Niles NJ. Basic concepts of health care human resource management. Burlington: Jones \& Bartlett Learning; 2019.

3. Fottler MD, Malvey D, Slovensky DJ. Handbook of healthcare management. Northampton: Edward Elgar Publishing, Incorporated; 2015.

4. Armstrong M, Taylor S. Armstrong's handbook of human resource management practice. 14th ed. London: Kogan Page; 2017.

5. Roussel L. Management and leadership for nurse administrators [Internet]. Burlington: Jones \& Bartlett Learning; 2013. Available from: https://books.google.com.eg/books?id=7KEyxKbRBj8C

6. Kovoor-Misra S. Crisis management: Resilience and change. London: SAGE Publications; 2019.

7. Martocchio JJ. Human resource management. Harlow, United Kingdom: Pearson Education; 2019.

8. Feldman HR, Alexander GR, Greenberg MJ, Jaffe-Ruiz M, McBride AB, McClure ML, et al. Nursing Leadership: A Concise Encyclopedia. 2nd ed. Springer Publishing Company; 2012.

9. Villajos E, Tordera N, Peiró JM, van Veldhoven M. Refinement and validation of a comprehensive scale for measuring HR practices aimed at performance-enhancement and employee-support. Eur Manag J. Elsevier Ltd; 2019;37:387-97.

10. Guest DE. Human Resource Management and Employee Well-being: Towards a New Analytic Framework. Wiley-Blackwell; 2017.

11. Liao H, Toya K, Lepak DP, Hong Y. Do they see eye to eye? Management and employee perspectives of high-performance work systems and influence processes on service quality. J Appl Psychol [Internet]. 2009 [cited 2021 Mar 25];94:371-91. Available from: /record/2009-02898-006

12. Buchbinder SB, Shanks NH. Introduction to health care management. 3rd ed. Burlington: Jones \& Bartlett Learning; 2019.

13. Hunt R. Introduction to community-based nursing. 5th ed. Philadelphia: Wolters Kluwer Health/Lippincott Williams \& Wilkins; 2009.

14. Finkelman A. Leadership and management for nurses: Core competencies for quality care [Internet]. Boston: Pearson Education; 2012. Available from: https://books.google.com.eg/books? id=obOuAAAAQBAJ

15. Karami A, Farokhzadian J, Foroughameri G. Nurses' professional competency and organizational commitment: Is it important for human resource management? PLoS One. United States; 2017;12:e0187863.

16. Lunnan R, Elizabeth Mercer Traavik L. Is the standardization of human resource practices perceived as fair across national cultures? Balt J Manag. Emerald Group Publishing Limited; 2009;4:127-48. 
17. Brown TA. Confirmatory factor analysis for applied research. 2nd ed. New York: Guilford Publications; 2015.

18. Tsang S, Royse CF, Terkawi AS. Guidelines for developing, translating, and validating a questionnaire in perioperative and pain medicine. Saudi J Anaesth. India; 2017;11:S80-9.

19. Meyer SM, Collier DA. An empirical test of the causal relationships in the Baldrige Health Care Pilot Criteria. J Oper Manag. 2001;19:403-26.

20. Schwirian PM. Evaluating the performance of nurses: a multidimensional approach. Nurs Res. United States; 1978;27:347-51.

21. Badri M, Abdulla M, AL-Khaili M. Quality of medical and health care services in light of the Malcolm Baldrige Quality Dimensions Award: Afield study of the hospital of the United Arab Emirates. J Gulf Arab Penins Stud. 2005;119:159-239.

22. Miloud $L$. The relationship between organizational socialization and professional performance among nurses: A study in public health institutions in Oran. ASJP. Bir El-Djir, Algeria: ASJP; 2016;10.

23. Beaton DE, Bombardier C, Guillemin F, Ferraz MB. Guidelines for the process of cross-cultural adaptation of self-report measures. Spine (Phila Pa 1976). United States; 2000;25:3186-91.

24. Tabassum N, Allana S, Saeed T, Dias JM. Content validity of a tool measuring medication errors. J Coll Physicians Surg Pakistan. 2015;25:623-4.

25. Polit DF, Beck CT. The content validity index: Are You sure you know what 's being reported? Critique and recommendations. 2006;489-97.

26. Sodhi JK, Sharma K, Kaur J, Brar MK. Development, validity and testing of patient handover documentation tool. Int J Healthc Sci. 2014;2:54-9.

27. Carmines EG, Zeller RA. Reliability and validity assessment. California: SAGE Publications; 1979.

28. Sharma J, Dhar RL, Tyagi A. Stress as a mediator between work-family conflict and psychological health among the nursing staff: Moderating role of emotional intelligence. Appl Nurs Res. W.B. Saunders; 2016;30:268-75.

29. Polit DF, Beck CT. Essential of nursing research: Appraising evidence for nursing practice. 7th ed. Philadelphia: Wolters Kluwer Health/Lippincott Williams \& Wilkins.; 2010.

30. Tavakol M, Dennick R. Making sense of Cronbach's alpha. Int. J. Med. Educ. IJME; 2011. p. 53-5.

31. Bolarinwa 0 . Principles and methods of validity and reliability testing of questionnaires used in social and health science researches. Niger Postgrad Med J. 2015;22:195-201.

32. Gile PP, Buljac-Samardzic M, Klundert J Van De. The effect of human resource management on performance in hospitals in Sub-Saharan Africa: a systematic literature review. Hum Resour Health. England; 2018;16:34.

33. Evans JR, Lindsay WM. Managing for quality and performance excellence. 10th ed. Boston: Cengage Learning; 2017.

34. Zink KJ. Human resources and organisational excellence. Total Qual Manag Bus Excell. Routledge; 2008;19:793-805.

35. Gyensare MA, Asare J. Relationship between human resource (HR ) practices and perceived performance of psychiatry nurses in Ghana. African J Bus Manag. 2012;6:2137-42. 
36. Gunawan J, Aungsuroch Y, Fisher ML. Competence-based human resource management in nursing: A literature review. Nurs Forum. 2019;54:91-101.

\section{Tables}

Table (1)

Content validity index of clarity and relevance.

\begin{tabular}{|lllllllllllll|}
\hline Items & 1 & 2 & 3 & 4 & 5 & 6 & 7 & 8 & 9 & 10 & 11 & 12 \\
\hline Clear CVI & 1 & .727 & .909 & 1 & 1 & 1 & 1 & 1 & .909 & .909 & 1 & 1 \\
\hline Relevant CVI & .909 & 1 & 1 & .727 & 1 & 1 & 1 & 1 & .909 & 1 & .811 & 1 \\
\hline Items & 13 & 14 & 15 & 16 & 17 & 18 & 19 & 20 & 21 & 22 & 23 & 24 \\
\hline Clear CVI & .818 & .909 & .1 & .909 & 1 & 1 & 1 & 1 & 1 & 1 & 1 & .909 \\
\hline Relevant CVI & 1 & 1 & 1 & .909 & 1 & 1 & 1 & 1 & 1 & 1 & .818 & 1 \\
\hline
\end{tabular}

Table (2)

Items loading of HRP scale.

\begin{tabular}{|lllllllllllll|}
\hline Items & 1 & 2 & 3 & 4 & 5 & 6 & 7 & 8 & 9 & 10 & 11 & 12 \\
\hline Items loading & .73 & .53 & .74 & .69 & .79 & .77 & .79 & .87 & .82 & .83 & .85 & .63 \\
\hline Items & 13 & 14 & 15 & 16 & 17 & 18 & 19 & 20 & 21 & 22 & 23 & 24 \\
\hline Items loading & .77 & .67 & .80 & .80 & .87 & .74 & .78 & .68 & .84 & .81 & .82 & .71 \\
\hline
\end{tabular}

Table (3)

Intra-class correlation coefficient ICC (intra-rater agreement) between the HRP scale items $(n=85)$.

\begin{tabular}{|c|c|c|c|c|c|c|c|c|c|c|c|c|}
\hline Items & 1 & 2 & 3 & 4 & 5 & 6 & 7 & 8 & 9 & 10 & 11 & 12 \\
\hline $\begin{array}{l}\text { ICC } \\
(r)\end{array}$ & $.85^{\star \star}$ & $.90 \star *$ & $.82^{\star \star}$ & $.91^{\star \star}$ & $.96^{\star \star}$ & 1 & .91 ** & $.90^{\star \star}$ & $.90 \star \star$ & 1 & .91 ** & .90 ** \\
\hline Items & 13 & 14 & 15 & 16 & 17 & 18 & 19 & 20 & 21 & 22 & 23 & 24 \\
\hline $\begin{array}{l}\text { ICC } \\
(r)\end{array}$ & $.85^{\star \star}$ & $.80 \star \star$ & .86 ** & $.78^{*}$ & $.76^{\star}$ & $.77^{\star \star}$ & $.89 * \star$ & .91. & $.94^{\star \star}$ & $.67 *$ & $.79 * \star$ & $.46^{\star \star *}$ \\
\hline
\end{tabular}




\section{Figures}

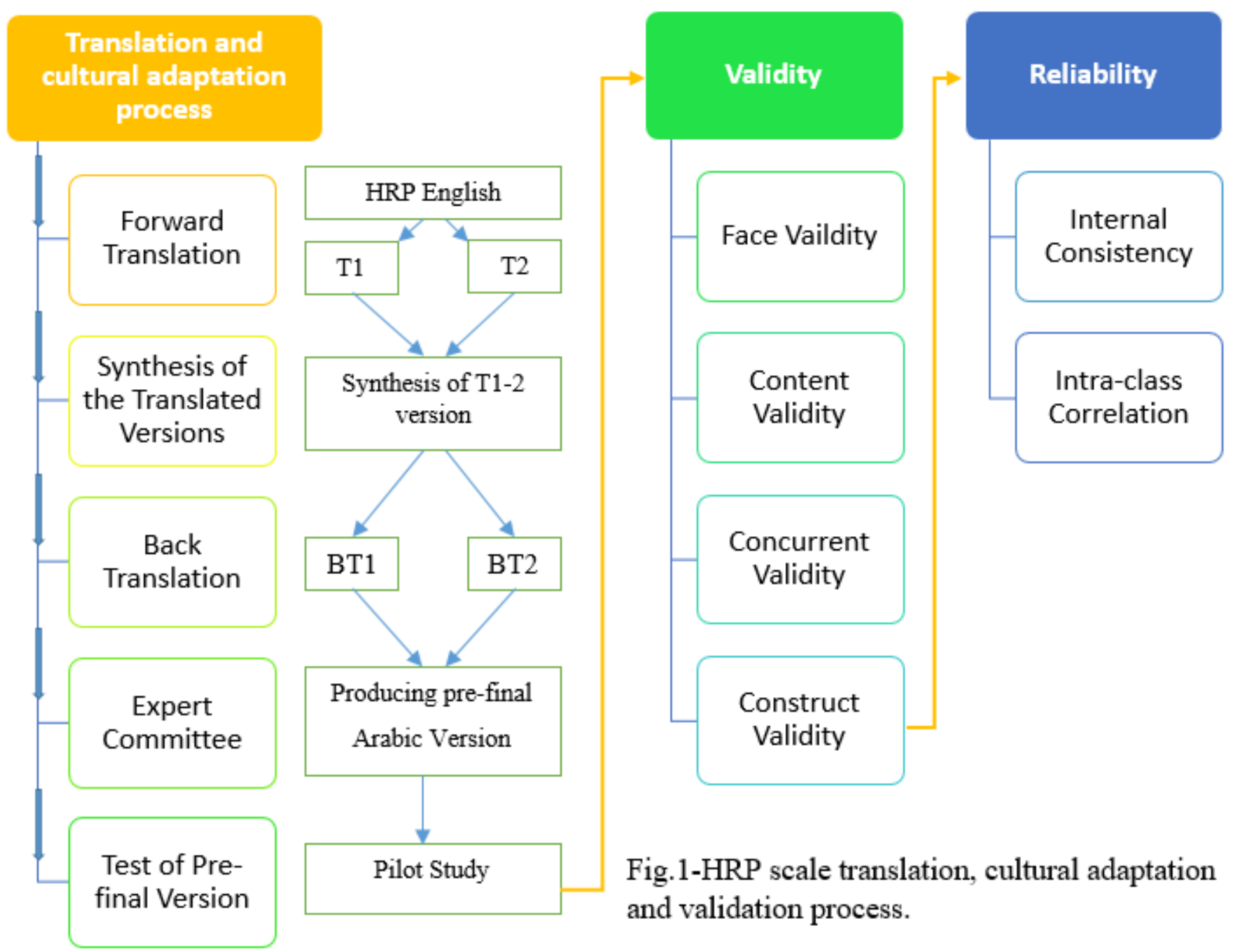

Figure 1

HRP scale translation, cultural adaptation and validation process. 